Ambiente \& Água - An Interdisciplinary Journal of Applied Science
ISSN 1980-993X - doi:10.4136/1980-993X
www.ambi-agua.net
E-mail: ambi-agua@agro.unitau.br

\title{
Ocorrência de Escherichia coli em fontes de água e pontos de consumo em uma comunidade rural
}

\author{
doi: 10.4136/ambi-agua.1301 \\ Received: 04 Feb. 2014; Accepted: 28 Mar. 2014 \\ Rosane Barbosa Lopes Cavalcante \\ Instituto de Pesquisas Hidráulicas (IPH / UFRGS), Porto Alegre, RS, Brasil \\ e-mail: rosanecavalcante@gmail.com
}

\section{RESUMO}

A falta de monitoramento das diferentes fontes de água e o desconhecimento da população das causas e problemas associados à contaminação concorrem para a alta incidência de doenças de veiculação hídrica em comunidades rurais. Neste contexto, este trabalho objetivou analisar a ocorrência de Escherichia coli, em diferentes fontes de água e pontos de consumo, na comunidade de Olho d'Água Grande, no semiárido alagoano. De modo complementar foram analisadas cor, turbidez e presença de coliformes totais. Todas as amostras analisadas apresentaram índices de E. coli acima do permitido para consumo humano segundo a legislação vigente. A verificação de contaminação dentro das residências analisadas, o armazenamento inapropriado nas residências e a ausência de medidas de desinfecção ressaltam a importância de intervenções adicionais à simples melhoria estrutural do abastecimento de água.

Palavras-chave: Escherichia coli, saneamento rural, abastecimento de água.

\section{Occurrence of Escherichia coli in water sources and point-of-use in a semi-arid rural community in Brazil}

\begin{abstract}
In low-income rural areas with a low education level, it is not uncommon that local environmental problems associated with water quality are unknown to the population. This contributes to a high incidence of water-related diseases. This paper aimed to analyze the presence of Escherichia coli in different water supply sources and point-of-use in the community of Olho d'Água Grande, in the semi-arid region of Alagoas, Brazil. The results showed that all the analyzed water sources in the community did not meet potability standards. Contamination verified inside the residences, improper storage in the residences, and the absence of disinfection measures underscore the importance of additional interventions besides structural improvement of the water supply system.
\end{abstract}

Keywords: Escherichia coli, rural sanitation, water supply. 


\section{INTRODUÇÃO}

Um dos grandes desafios do saneamento brasileiro é desenvolver programas de saneamento em comunidades isoladas que exigem soluções independentes e estratégias diferenciadas que respeitem a identidade natural e social do lugar (Hosoi, 2011). Altos índices de contaminação bacteriológica em fontes de água de áreas rurais foram observados em diversas localidades do Brasil (Amaral et al., 2003; Costa et al., 2006; Oliveira, 2008; Rocha et al., 2006; Gomes et al., 2011). Na região semiárida, os problemas relacionados à qualidade das fontes de água são ainda maiores, devido à necessidade de fontes alternativas que complementem o abastecimento nos períodos de seca.

A falta de monitoramento destas fontes e o desconhecimento da população das causas e problemas associados à contaminação da água concorrem para maior incidência de doenças de veiculação hídrica. Globalmente, há aproximadamente 1,7 bilhões de casos de doenças diarreicas e 4 milhões de crianças com menos de 5 anos morrem de diarreia todo ano (WHO, 2013). No Brasil, o número total de internações por diarreia apenas nos 100 municípios brasileiros mais populosos representa $20,7 \%$ do total das internações de crianças (Kronemberger, 2013).

A melhoria das fontes de abastecimento é usualmente uma das principais estratégias no combate à diarreia. A disponibilidade de água influencia as condições de saneamento, renda familiar, higiene e, portanto, a saúde pública (Hunter et al., 2010). Entretanto, a falta de manutenção e gestão apropriada da infraestrutura existente (Margulis et al., 2002) e ausência de melhorias nas condições de saneamento e educação da população, podem contribuir para resultados não satisfatórios.

A importância de um sistema de água encanada na redução de diarreia em crianças tem se apresentado bastante dependente do grau de educação da mãe, especialmente em famílias pobres (Jalan e Ravaillon, 2003). Além disso, é frequentemente observado que a qualidade microbiológica da água armazenada no ponto de consumo é mais baixa que na fonte, sugerindo uma contaminação na coleta, transporte, armazenamento e extração da água (Wright et al., 2004; Varghese, 2004). Estes resultados apontam para o fato que amostragens nos locais de consumo podem melhor refletir a qualidade da água que amostragens nas fontes.

Neste contexto, este trabalho objetivou analisar a ocorrência de E. coli na água utilizada para consumo de uma comunidade rural do semiárido brasileiro entre diferentes formas de abastecimento e da fonte de água ao ponto de consumo, tendo em vista a importância destes resultados na determinação de ações de combate à diarreia e outras doenças de veiculação hídrica.

\section{MATERIAIS E MÉTODOS}

\section{1. Área de estudo: Comunidade de Olho d'Água Grande, Santana do Ipanema / AL}

O presente estudo foi desenvolvido em 2008 na comunidade Olho d'Água Grande, pertencente ao município de Santana do Ipanema (região semiárida de Alagoas). A comunidade não possui sistema de abastecimento de água, rede de esgoto ou coleta de lixo. As 68 famílias residentes na região, quase inteiramente de pequenos agricultores, necessitam se deslocar à sede do município ou ao povoado mais próximo para obter serviços básicos como postos de saúde e escolas.

As chuvas na região são mal distribuídas e o relevo é acidentado, dificultando o acesso na época chuvosa. O núcleo principal de casas localiza-se próximo à fonte de água Poço do Vicente, enquanto as demais residências encontram-se esparsamente distribuídas. 
As principais fontes de água da comunidade são reservatórios construídos para armazenamento de duas nascentes localizadas na comunidade, denominadas pelos moradores de Poço do Pedrão e Poço do Vicente (Figura 1)

A única proteção identificada contra o escoamento superficial ou ao uso da água no local foram tampas instaladas no Poço do Vicente.
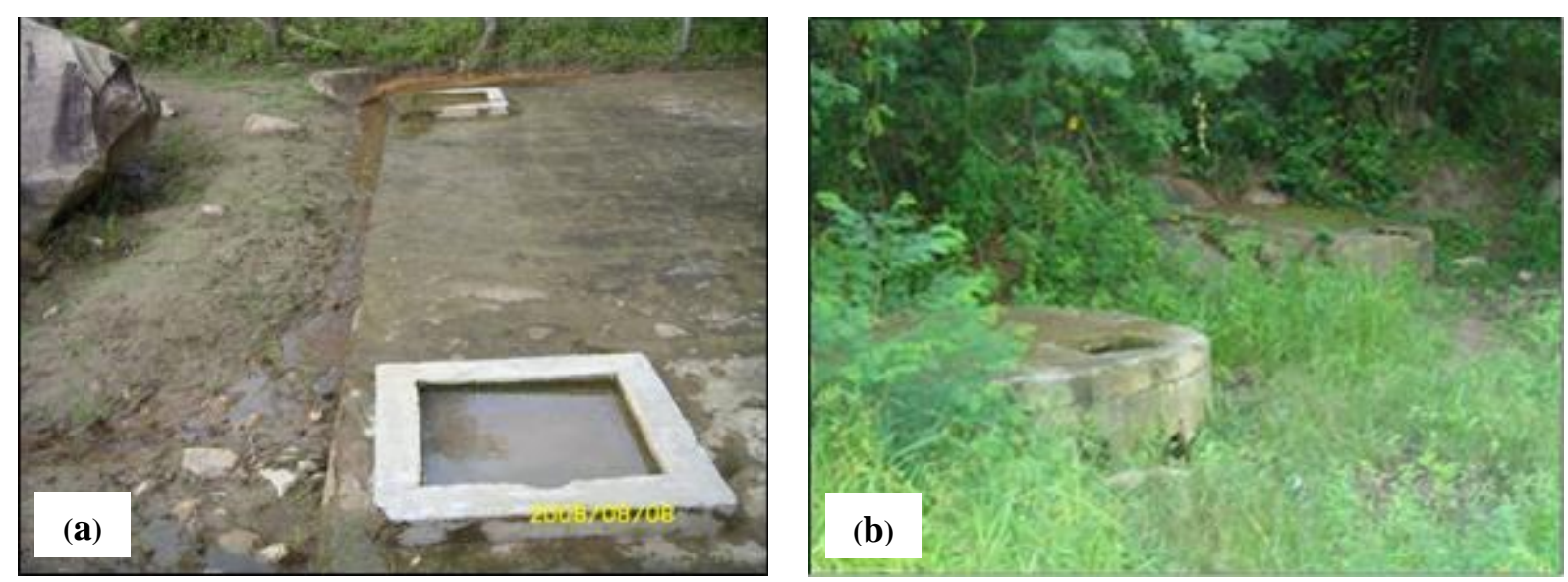

Figura 1. Instalações das principais fontes de água da comunidade: Poço do Vicente (a) e Poço do Pedrão (b).

O topo do Poço do Vicente encontra-se no nível do solo e está localizado a $434 \mathrm{~m}$ de altitude. Em 2007, por iniciativa de uma organização não governamental, o reservatório foi conectado a uma cisterna de $30.000 \mathrm{~L}$ com filtro de disco na tubulação de entrada, sendo a população local orientada a retirá-lo e limpá-lo. A partir deste reservatório a água é distribuída por gravidade para 22 residências. Na residência mais afastada, foi instalada uma caixa d'água de 5.000 L, na qual os moradores que não possuem água encanada usualmente buscam água.

No verão há necessidade de racionamento da distribuição de água, enquanto no inverno ocorre transbordamento do Poço do Vicente.

O Poço do Pedrão está localizado a $527 \mathrm{~m}$ de altitude, havendo apenas uma residência da comunidade em cota superior ao mesmo. Nenhuma melhoria foi feita nesta fonte desde a construção de dois reservatórios rasos de encosta interligados na década de 1980. A água é canalizada para três residências, havendo caixa d'água e cisterna em apenas uma delas. No verão, algumas famílias buscam água diretamente na fonte. Como o acesso é difícil, alguns usos da água, como lavar roupas, são feitos no próprio local. No inverno, ocorre transbordamento dos reservatórios, mas nenhuma família busca água no local, optando por utilizar água de cisternas ou outras fontes mais acessíveis.

A principal fonte de água da população que reside afastada dos pontos de distribuição de água dos principais reservatórios consiste na água da chuva armazenada em cisternas. Poucas cisternas, entretanto, garantem água para o consumo durante o verão e muitas possuíam vazamentos. Há também famílias que utilizam a água de barragens para todos os usos domésticos, inclusive consumo humano durante o verão.

\subsection{Coleta e análise de amostras}

As fontes de água utilizadas pela comunidade foram visitadas a fim de diagnosticar a situação das mesmas e coletar amostras para análises laboratoriais. Também foram verificadas causas potenciais de contaminação no sistema de abastecimento a partir da coleta de amostras em diferentes pontos do sistema até as residências e da verificação das formas de armazenamento de água nas residências. 
Os parâmetros analisados como indicadores da qualidade da água foram número de coliformes totais e E. coli, turbidez e cor. A detecção do E. coli como prática de controle microbiológico de qualidade da água foi escolhida por ser esta uma tendência internacional e ser o parâmetro adotado no Brasil (Portaria no 2914/2011 do Ministério da Saúde). Os parâmetros turbidez e cor aparente estão relacionados à aceitação dos consumidores e desempenham papel preponderante na eficiência da desinfecção (Daniel, 2001). O atendimento ao padrão de turbidez também complementa as exigências nacionais relativas aos indicadores microbiológicos.

Para a determinação destes parâmetros foram utilizados o turbidímetro de bancada modelo AP 2000 IR, o comparador visual modelo Nessler quanti200 e o método Colilert para quantificação de coliformes totais e E. coli. As análises foram realizadas no Laboratório de Saneamento Ambiental da Universidade Federal de Alagoas.

Os pontos de coleta para avaliação da qualidade da água foram selecionados de modo a abranger as principais fontes de abastecimento de água da comunidade:

- Ponto 1: Fonte de água Poço do Pedrão;

- Ponto 2: Cisterna conectada ao Poço do Vicente, a partir da qual é feito o abastecimento a 22 casas;

- Ponto 3: Residência 1 - Torneira antes da caixa d'água (residência abastecida com água encanada do sistema de abastecimento com água do Poço do Vicente);

- Ponto 4: Residência 1 - Caixa d'água;

- Ponto 5: Residência 1 - Torneira após a caixa d'água;

- Ponto 6: Caixa d'água do sistema de abastecimento do Poço do Vicente localizada na casa mais afastada da fonte, onde diferentes moradores da comunidade buscam água;

- Ponto 7: Residência 2 (que utiliza captação de água da chuva com armazenamento em cisterna) - água coletada da torneira;

Os locais de coleta 3 e 4 foram adicionados, a fim de verificar as causas da contaminação observadas no primeiro dia de coleta no Ponto 5.

As amostras foram coletadas nos dias 19 de julho, 24 de julho, 08 de agosto, 24 de agosto e 12 de outubro. Não foi possível a coleta da amostra na casa do morador com cisterna nos dias 08 e 24 de agosto. Como a cisterna já havia secado, a amostra coletada neste local no dia 12 de outubro foi obtida do Ponto 6.

\section{RESULTADOS}

Os valores encontrados para turbidez (Figura 2) e cor aparente (Figura 3) foram, em quase sua totalidade, superiores ao padrão aceitável para consumo humano, correspondentes a 5 uT e 15 uH, respectivamente, conforme Portaria $n^{\circ}$ 2914/2011 do Ministério da Saúde (Brasil, 2011). Apenas o Ponto 7, referente à casa do morador que utiliza cisterna, apresentou valores abaixo dos valores máximos permitidos nas duas primeiras coletas, quando utilizava água captada da chuva.

As Figuras 4 e 5 mostram o resultado das análises de E. coli e coliformes totais das análises coletadas nos dias 19 de julho, 24 de julho e 08 de agosto. Não foi possível a determinação destes parâmetros para as demais amostras. Todas as amostras estavam fora dos padrões de potabilidade, conforme Portaria 2914/2011 do Ministério da Saúde que corresponde à ausência de E. coli em $100 \mathrm{~mL}$ de amostra. Os menores valores encontrados de E. coli e coliformes totais foram os observados nas amostras coletadas nos Pontos 1 e 7, correspondentes ao Poço do Pedrão e à casa que utilizava água de cisterna.

O resultado da primeira análise, confirmado pelas seguintes, apontou altos índices de E. coli e de coliformes totais para o Ponto 5 (torneira da casa do morador com água encanada do poço do Vicente). 
Os valores eram, inclusive, superiores ao encontrado em outros pontos da mesma rede de abastecimento (Figuras 4 e 5). Os resultados obtidos nos demais pontos ao longo do sistema de água da residência na análise do dia 08 de agosto mostraram que a água chegava à casa do morador com qualidade similar a do Poço do Vicente. Na visita à residência, percebeu-se que a caixa d'água encontrava-se sem limpeza e não possuía tampa.

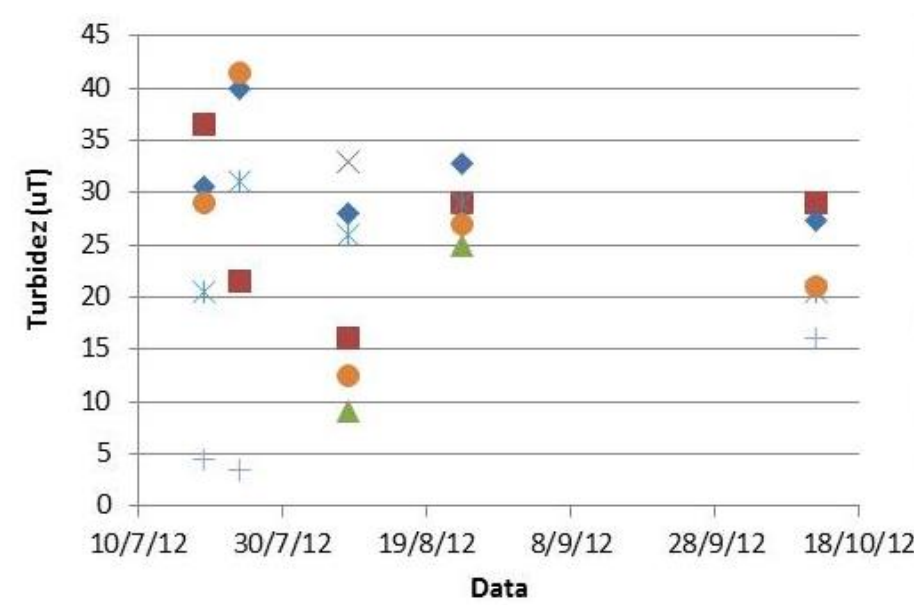

1 - Poço do Pedrão

2 - Cisterna ligada ao Poço do Vicente

3 - Residência 1 - Antes da caixa d'água

× 4 - Residência 1 - Caixa d'água

* 5 - Residência 1 - Após a caixa d'água

- 6 - Caixa d'água onde buscam água

+ 7 - Residência 2 - Captação

da água de chuva

Figura 2. Resultado das análises de turbidez (uT).

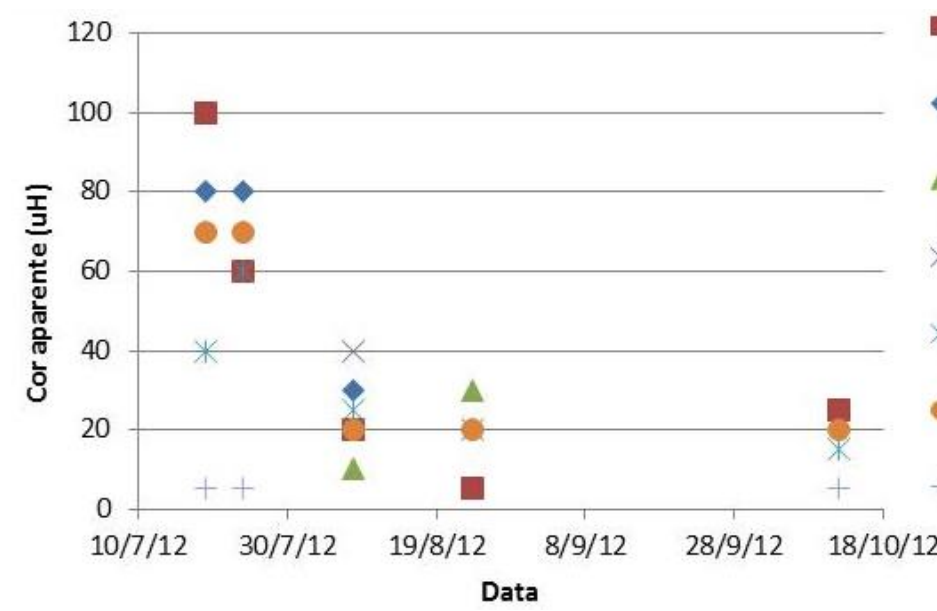

1 - Poço do Pedrão

2 - Cisterna ligada ao Poço do Vicente

$\triangle 3$ - Residência 1 - Antes da caixa d'água

×4 - Residência 1 - Caixa d'água

* 5 - Residência 1 - Após a caixa d'água

- 6 - Caixa d'água onde buscam água

+ 7 - Residência 2 - Captação da água de chuva

Figura 3. Resultado das análises de cor aparente (uH).

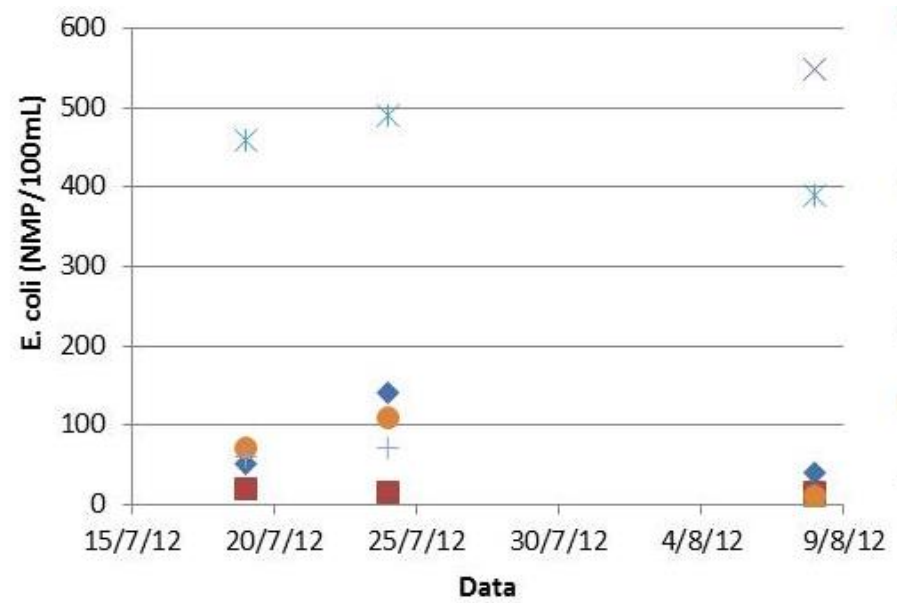

1 - Poço do Pedrão

2 - Cisterna ligada ao Poço do Vicente

$\triangle 3$ - Residência 1 - Antes da caixa d'água

$\times 4$ - Residência 1 - Caixa d'água

* 5 - Residência 1 - Após a caixa d'água

- 6 - Caixa d'água onde buscam água

+ 7 - Residência 2 - Captação da água de chuva

Figura 4. Resultado das análises de E. coli (NMP/100 mL). 

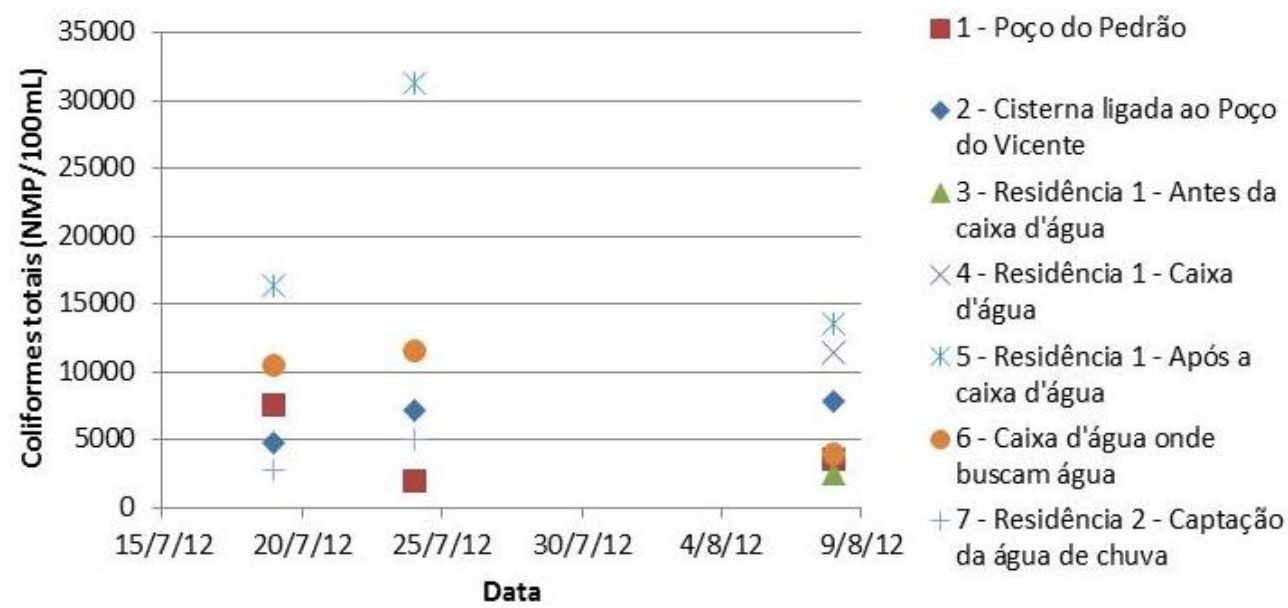

Figura 5. Resultado das análises de coliformes totais (NMP/100 mL).

\section{DISCUSSÃO}

Como observado em outras áreas rurais no Brasil (Amaral et al., 2003; Costa et al., 2006; Oliveira, 2008; Rocha et al., 2006; Gomes et al., 2011), as fontes de água da comunidade de Olho d'Água Grande também apresentaram presença de E. coli. A comunidade necessita de melhorias significativas no que se refere à proteção das fontes de abastecimento, abastecimento de água e disposição dos esgotos domésticos. Todas as fontes de água analisadas apresentaram $E$. coli fora dos padrões de potabilidade, necessitando de medidas de proteção das fontes e desinfecção antes do consumo. O Poço do Pedrão apresentou os menores números de $E$. coli, o que pode ser devido ao difícil acesso ao poço, aliado a sua elevação em relação ao solo e a baixa ocupação do solo ao redor da fonte.

Sobre a contaminação da água verificada na residência com armazenamento de água da chuva, os resultados de Baguma et al. (2010) sugerem que instruções de uso, incluindo riscos à saúde, devem ser utilizados para melhorar a gestão de água doméstica dessas fontes. $\mathrm{O}$ desvio dos primeiros milímetros de chuva e a periódica adição de desinfetantes são sugeridos por Kahinda et al. (2007) como procedimentos de manutenção do sistema para melhorar a qualidade da água assim obtida.

Quanto ao alto índice de E. coli encontrados na casa do morador que recebia água encanada da rede de abastecimento do Poço do Vicente, verificou-se que a água chegava à casa do morador com qualidade similar a da fonte, descartando a hipótese de contaminação na rede de abastecimento. Entretanto, destaca-se que as análises de E. coli em todos os pontos dentro da residência só foi possível em uma análise (08 de agosto). Na visita à residência, percebeu-se que a caixa d'água encontrava-se sem limpeza há algum tempo e não possuía tampa, sendo identificado como local de contaminação.

Esta contaminação identificada entre fonte de água e ponto de consumo ressalta a importância de intervenções adicionais à melhoria estrutural do abastecimento de água, em especial medidas de saneamento, armazenamento apropriado nas residências e medidas adicionais para desinfecção. O simples ato de tampar os reservatórios causa redução significativa na contagem de coliformes totais e termotolerantes (Wright et al., 2004). Embora a importância da contaminação da água na residência ainda seja matéria de discussão, intervenções no sentido de reduzir esta contaminação tem reduzido significativamente a incidência de diarreia (Gundry et al., 2004).

Os resultados corroboram com o apresentado por Hosoi (2011) de que além do aporte financeiro, os sistemas descentralizados demandam apoio técnico, operacional e social para garantir a continuidade da gestão e qualidade dos serviços. Santos Jr. et al. (2013) apontam a falta de informação da população em geral, especialmente da população mais jovem, como 
um dos principais desafios enfrentados para conservação e uso racional da água no semiárido brasileiro.

A metodologia utilizada, entretanto, não permitiu explicar alguns dos resultados encontrados, a exemplo da menor turbidez verificada no dia 08 de agosto e maior cor aparente no mês de julho. A variação da precipitação aliada à continuação das análises poderia esclarecer estas questões.

\section{CONCLUSÕES}

A água utilizada pela comunidade de Olho d'Água Grande foi identificada como um importante fator de risco à saúde da população, visto que todas as fontes de água analisadas apresentam índices de coliformes totais e E. coli acima do permitido para consumo humano. A água de cisternas para captação da água da chuva e da fonte de água com acesso mais difícil apresentaram os menores valores de coliformes no período de análise, apresentando-se como boas alternativas para abastecimento nas residências não contempladas pelo atual sistema de abastecimento.

Entretanto, a verificação de contaminação dentro da residência analisada, o armazenamento inapropriado na residência e a ausência de medidas de desinfecção ressaltam a importância de intervenções adicionais à melhoria estrutural do abastecimento de água. Ações para melhoria do saneamento, de educação sanitária, monitoramento na fonte e manutenção dos sistemas existentes são essenciais.

Sugere-se um acompanhamento da qualidade de água nas fontes e nas residências da comunidade, especialmente no período de seca quando há um aumento do uso de fontes alternativas, e das condições de saúde da população que identifique a ocorrência de doenças ligadas à falta de saneamento básico adequado.

\section{REFERÊNCIAS}

AMARAL, L. A.; NADER FILHO, A.; ROSSI Jr., O. D.; FERREIRA, F. L. A.; BARROS, L. S. S. Água de consumo humano como fator de risco à saúde em propriedades rurais. Revista de Saúde Pública, v. 37, n. 4, p. 510-514, 2003. http://dx.doi.org/10.1590/S0034-89102003000400017

BAGUMA, D.; LOISKANDL, W.; JUNG, H. Water management, rainwater harvesting and predictive variables in rural households. Water Resources Management, v. 24, p. 3333-3348, 2010. http://dx.doi.org/10.1007/s11269-010-9609-9

BRASIL. Ministério da Saúde. Portaria n ${ }^{\circ} 2914$ de 12 de dezembro de 2011. Dispõe sobre os procedimentos de controle e de vigilância da qualidade da água para consumo humano e seu padrão de potabilidade. Diário Oficial [da] República Federativa do Brasil, Poder Executivo, Brasília, DF, 12 mar., 2011.

COSTA, R. da C.; CIRILO, J. A.; MAIA, A. Z.; LACERDA Jr., H. B. de. Diagnóstico das condições sanitárias de distritos semi-urbanos localizados em clima semi-árido. In: SIMPÓSIO DE RECURSOS HÍDRICOS DO NORDESTE, 8., 2006, Gravatá. Anais... Gravatá: ABRH, 2006.

DANIEL, L. A. (coord.) Processos de desinfecção e desinfetantes alternativos na produção de água potável. Rio de Janeiro: RiMa; ABES, 2001. 
GOMES, M. C. R. L.; SOUZA, J. B.; FUJINAGA, C. I. Estudo de caso das condições de abastecimento de água e esgotamento sanitário dos moradores da estação ecológica de Fernandes Pinheiro (PR). Ambiência, v. 7, n. 1, p. 25-38, jan./abr. 2011.

GUNDRY, S.; WRIGHT, J.; CONROY, R. A systematic review of the health outcomes related to household water quality in developing countries. Journal of Water and Health, v. 02, n. 01, p. 2004.

HOSOI, C. Comunidades isoladas exigem um saneamento sob medida. Revista DAE, n. 187, p. 4-12, set. 2011.

HUNTER, P. R.; MacDONALD, A. M.; CARTER, R. C. Water supply and health. Plos Medicine, v. 7, n. 11, 2010. http://dx.doi.org/10.1371/journal.pmed.1000361.g004

JALAN, J.; RAVALLION, M. Does piped water reduce diarrhea for children in rural India? Journal of Econometrics, v. 112, p. 153-173, 2003. http://dx.doi.org/10.1016/S03044076(02)00158-6

KAHINDA, J. M.; TAIGBENU, A. E.; BOROTO, J. R. Domestic rainwater harvesting to improve water supply in rural South Africa. Physics and Chemistry of the Earth, v. 32, p. 1050-1057, 2007. http://dx.doi.org/10.1016/j.pce.2007.07.007

KRONEMBERGER, D. Análise dos impactos na saúde e no Sistema Único de Saúde decorrentes de agravos relacionados a um esgotamento sanitário inadequado dos 100 maiores municípios brasileiros no período 2008-2011. Relatório Final. 2013. Disponível em: http://www.tratabrasil.org.br/datafiles/uploads/drsai/Relatorio-FinalTrata-Brasil-Denise-Versao -FINAL.pdf. Acesso em julho de 2013.

MARGUliS, S.; HUGHES, G.; GAMBRILL, M.; AZEVEDO, L. G. T. Managing water quality: mainstreaming the environment in the water sector. Washington: World Bank, 2002.

OLIVEIRA, D. G. S. Potabilidade da água de fontes alternativas (nascente, poço raso e poço profundo) na zona rural de Formiga (MG) e sua relação com a condição ambiental da microbacia. 2008. Dissertação (Mestrado) - Universidade do Estado de Minas Gerais, Divinópolis, 2008.

ROCHA, C. M. B. M.; RODRIGUES, L. S. COSTA, C. C.; OLIVEIRA, P. R.; SILVA, I. J.; JESUS, E. F. M. et al. Avaliação da qualidade da água e percepção higiênico-sanitária na área rural de Lavras, Minas Gerais, Brasil, 1999-2000. Cadernos de Saúde Pública, v. 22, n. 9, p.1967-1978, 2006. http://dx.doi.org/10.1590/S0102-311X2006000900028

SANTOS JR., J. A.; BARROS JR., G.; SANTOS, J. K. L.; BRITO, E. T. F. S. Uso racional da água: ações interdisciplinares em escola rural do semiárido brasileiro. Ambi-Agua, Taubaté, v. 8, n. 1, p. 263-271, 2013. http://dx.doi.org/10.4136/ambi-agua.1075

VARGHESE, A. A comparative risk approach to assessing point-of-use water treatment systems in developing countries. In: LINKOV, I.; RAMADAN, A. B. (Eds.). Comparative risk assessment and environmental decision making. New York: Springer, 2004.

WORLD HEALTH ORGANIZATION - WHO. Diarrhoeal disease. Fact sheet $\mathbf{N}^{\circ} \mathbf{3 3 0}$. World Health Organization, 2013. Disponível em: <http://www.who.int/mediacentre/ factsheets/fs330/en>. Acesso em: maio 2013. 
WRIGHT, J.; GUNDRY, S.; CONROY, R. Household drinking water in developing countries: a systematic review of microbiological contamination between source and point-of-use. Tropical Medicine and International Health, v. 9, n. 1, p. 106-117, 2004. http://dx.doi.org/10.1046/j.1365-3156.2003.01160.x 